\title{
Impact of Information Technology on Internal Supply Chain Management Implementation of RFID Tags
}

\author{
Khan S., Asim M., and Manzoor S.
}

\begin{abstract}
This research is related to the effects produced by Information technology on the Internal Supply Chain Management of the companies. It tells how the organization works through IT. RFID tags within the organization are associated with multiple advantages especially it is beneficial for managing the supply chain. The cost efficiencies \& costeffectiveness are promoted by multiple elements. RFID is a path towards the future. The future wants everything which is not only flexible and innovative but also the least expensive in order to give the best customer service. It is represented by the study that through RFID tags the major benefit attain is that data transfer is easy. Furthermore, it has better data capturing quality.
\end{abstract}

Keywords-Information Technology; Supply Chain Management; RFID Tags

\section{INTRODUCTION}

The store network the board is a significant idea for overseeing and arranging all exercises that are remembered for acquirement and sourcing, coordination the board and change exercises. It regularly includes cooperation and coordination with accomplices that might be middle people, providers, clients, outsider help offerors. The RFID Known as Radio Frequency Identification (RFID) is a significant innovation that aides in following the stock inside an inventory network. It can help in physical stream and synchronizing the progression of merchandise over a store network from a producer to the outlets and buyers at the perfect time and spot. RFID can follow products by store network and secure fake. It additionally supports to diminish down the stock things [1] [7]. There is no such doubt that RFID is not valuable for promoting supply chain efficiency and inventory management. The RFID promises in transforming the supply chain management by offering information on products flow by a value chain. The tags can be utilised at phases within the supply chain on pallets, containers, packaging, individual products and boxes [5] [8]. There are several challenges faced by adopting RFID, these are dual system management commitment, operational automation, cost challenges, patent and legal challenge, selection of software and hardware, support of technology for purpose of adoption. The goals of this research are:

1. To explore the understanding of IT, internal SCM and RFID Tags

2. To evaluate the common challenges and barriers faced by implementing RFID tags

3. To examine the steps involved in the implementation process

4. To understand standards, components and the frequencies of RFID

The main two research questions for the study are:
- What is the major impact of IT on ISCM through implementing RFID tags system?

- What are the challenges commonly faced for implementing RFID tags?

The research holds a significant place in understanding supply chain management within an organization. The companies require IT techniques and methods for enabling the integration of internal functions of the business. This can support companies for becoming efficient, promoting productivity and responding rapidly to a need of customers [2] [25]. The SCM system is the information process for transportation management, warehousing, logistics management, manufacturing, inventory and customer management. The organizations can deed the advances within IT techniques and methods that can enable the addition of external business operations. The companies may become extended through enabling a process of connectivity, suppliers, business partners and the customers [4].

There are three main levels such as strategic, operations and tactical. These levels of relationships are characterized by sharing information and behaviour of supply chain organizations. The RFID is a well-known tool used in a business for some perspective of business including the SCM. The SCM within an RFID is a developing technology that supports for making and being capable of close cooperation of SCM partners through visibility on a realtime basis [5] [23]. This research holds a significant importance because various companies have adopted IT technologies and systems, such as Barcode system and RFID to improve its operations, this has made the research to become essential for being conducted to identify various areas, and evaluate pros and cons for adopting and implementing RFID tags system within an internal supply chain management system [7] [10].

\section{LITERATURE REVIEW}

This section of the research study presents the evidence and data from previous researches from well-known journals, and articles. Number of studies that are carried out helps to identify various factors that contribute to impacting ISCM within an organisation, specifically the process of implementing RFID tags [8] [25].

The IT sector is realised as a problem holding importance for the system of RFID for supporting SCM. It also presents various perspectives through modelling item-level data and information visibility in general [12] [10]. The enterprises also use RFID for attaining an organisational change and managing the development in a competitive environment. 
The technology of RFID is significant for supporting a discussion based on time in a SCM. While, RFID is also considered to produce various benefits within supply chain management and providing insight into the competitive sight as the value of RFID.

The research study reveals RFID tags to improve visibility and traceability of processes and products, with the speed of the process, increasing efficiency, decreasing the losses of inventory, and improving the accuracy of information [15] [21]. The applications of RFID within SCM takes the advantage of technology that has an objective for accelerating process and decreasing down the cost but RFID characteristics are found within a latest information with respect to time and helping in process of making a decision. For purpose of executing a RFID system, the organisation is required to present the issues of cost, rules, technology development and international standards. The RFID technologies can promote the performance of the supply chain at various ratios [22] [25].

Within the context of the supply chain, RFID has various benefits, the readers can read various tags in a simultaneous way without needing a line of sight or the involvement of the individual. This may cut inventory control, cut checkout, and loss of the prevention cost. The RFID can promote a performance of supply chain by asset tracking, product recall and product origin tracing [19].

The demand planning is a common challenge that presents a lack of reliable, timely and adequate data. RFID can provide information related to inventory of work in processes finished goods and the transit. The RFID enables a process of automation for instance, cross-docking, picking, and shelving [17] [23]. The functions are consolidated and logistic is costly if it is not dispatching a correct customer at the right time.

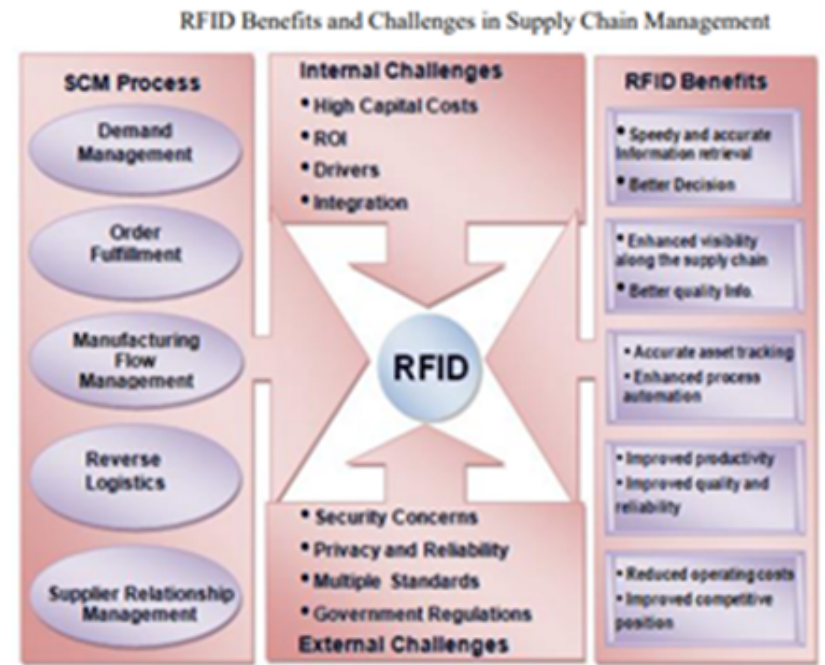

Fig. 1. RFID Benefits and Challenges in Supply Chain Management [4]

The most known selection of tag for using a supply chain is a passive tag that takes impacts in the UHDF is a range of frequency. The tags also use to differentiate through the capability of data storage. The tags differ through a data storage capability there are most common two main classifications of RFID tags these are READ-ONLY TAGS and READ/WRITE TAGS [4].

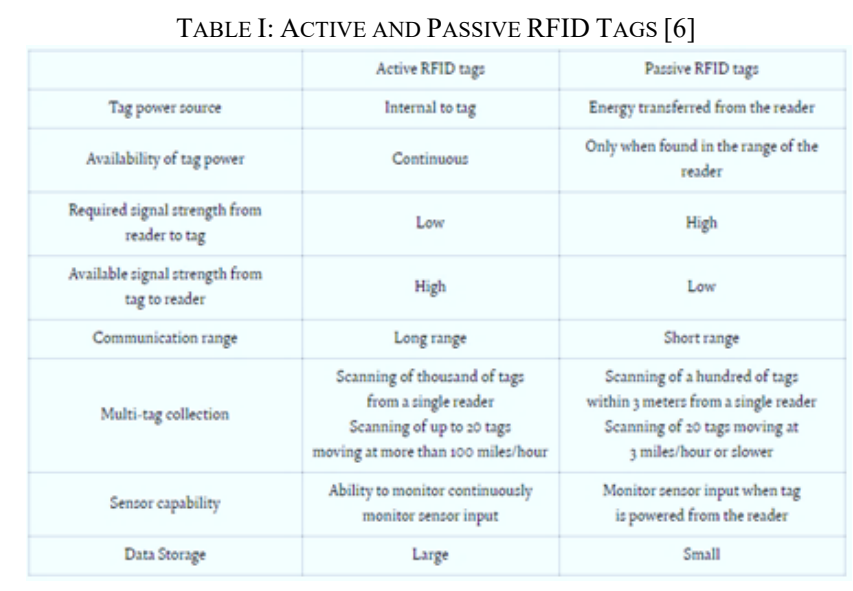

In total the existing areas are three classifications of RFID tags these are familiar to the consumer that uses the technology, these are active, passive and semi-passive. Taking the purchase of tags for various scenarios, pinpointing the type of tag to integrate and use in operation may be tricky [9]. The active tag has its own power source and transmitter that is an availability of batters present on a tag. It is a UHF solution and the range of reading may extend to $100 \mathrm{~m}$ in certain instances. The active tags are expensive and larger but commonly used in tracking a large asset, such as cargo containers, machines, and vehicles. The active tags have a sensor that measures, light, transmit temperature, humidity, vibration data and other objects [15].

The passive RFID tag solution presents the reader antenna for sending the sign to the tag and used to control over the tag and mirroring the vitality to a peruser. There is different latent including low recurrence. High recurrence and ultrahigher recurrence framework [10] [13]. Its read range is regularly shorter than a functioning tag and restricted through the intensity of radio sign. The third kind of tag is a half and half sort, known as, battery assistive latent, that joins a force source in an uninvolved label arrangement. The force source underpins guaranteeing the vitality that is caught from the peruser that may mirror the sign and improves for perusing the distance and transferring rates. Unlike the active type, BAP tags do not have their personal transmitters [20].

There are various benefits of implementing RFID technology in ISCM few among them are improved quality for capturing the data, the RFID approach helps to capture data in an accurate and rapid way. The electronic data collection with RFID use to avoid transcription when used for collecting data on a large number. The second benefit is decreased capital costs, it helps to decrease down the cost for providing control of assets or stocks. This can help for keeping on track for business, for example, computing technology, portable devices and test equipment [16] [21]. Using an RFID system can help in attaining access to the control system by using RFID and contributing to the business premises and improved security. The tagging of assets and stock makes simple for tracking the inventory shrinkage and tags that may be used to fight in opposition to product counterfeiting [14].

The major challenge regarding RFID technology is the costing of the RFID system. The recent study revealed RFID 
tag can range from the 2 cents per tag to upward of $\$ 50.00 /$ tag being dependent over the capacities. The tags may be disposable or reusable and have the costs that are associated [17]. The tags that are reusable have increased pricing but need standardized cleaning. The technical limitations for instance, RFID tag, system errors, interference with medical materials, interoperability with information technology obstruct the adoption [17]. It is tough to grasp the technology, knowing and understanding various frequencies and tags, as using the RFID equipment it can be a major challenge. The managers need to be up over technology so they may train employees on RFID and workflow. There are four basic levels of challenges faced while implementing the RFID system, these are fundamental, technical, security and privacy problems and governmental regulations.

TABLE II: RFID IMPLEMENTATION CHALLENGES [6]

\begin{tabular}{|c|l|}
\hline Levels & \multicolumn{1}{|c|}{ Challenges } \\
\hline Fundamental & $\begin{array}{l}\text { High capital costs } \\
\text { Challenges in finding the ROI } \\
\text { Challenges in finding the "drivers" for adoption }\end{array}$ \\
\hline Technical & $\begin{array}{l}\text { - Imperfect read-rates } \\
\text { Unproven systems } \\
\text { - Problems with assembling low-cost tags } \\
\text { Uncertainty about the role of the middleware }\end{array}$ \\
\hline Security & $\begin{array}{l}\text { Lack of in-house experts to implement RFID } \\
\text { - Concems regarding the compromise of data during } \\
\text { wireless transmission }\end{array}$ \\
\hline $\begin{array}{l}\text { Uncertainty around security of data storage and } \\
\text { physical security of storage site }\end{array}$ \\
\hline Government Regulations
\end{tabular}

RFID innovation can produce store network combination because of the joint effort sum and trust it requires. The innovation is a data sharing framework, that licenses accomplices to trade data about interest stock and estimating, from crude materials are done merchandise. In the event that an organization is incorporated with providers on the off chance that they work either in resistance or support for the selection of RFID [5] [17].

It also allows the It additionally permits the stockroom stock administration, guaranteeing that sent item adjusts to genuine transportation request, forestalling the stock-outs at a degree of offers, refreshing administrators with period of generation, improving a degree of efficiency, reducing the paperwork, current phase of a production, enhancing a clarity of process in context of product development by mean of supply chain reducing cost of lab our, rendering an inventory forecasting adequate [18] [23]. This technology supports for tracking an item that is tagged transversely a supply chain.

Instead of the advantages of RFID, there are a few disservices corresponded with an innovation that should be handled through firms. The RFID labels include a huge scope of information that in certain raise protection concerns [14] [21]. The exact investigation did present that $73 \%$ of 129 clients might want RFID labels on the item acquired for evacuating at a checkout level because of worries of clients with respect to information put away on labels. Notwithstanding protection concerns, while information put away on a tag doesn't observe the standard arrangement that can be known through different firms over the inventory network that can bring about bogus information stockpiling on a database of firms [20].

The usage of RFID permits to monitor the elements as they use to move among organisational divisions, Tags are able to take the information, a tagged material and product may be tracked at various positions. The data is stored in the RFID tag's microchip that is associated with an antenna [22] [25]. The tag chip includes a memory that stores an item's electronic item code and data of factors. The RFID reader is a system that is associated gadget with receiving wire and peruses and tracks data from labels of RFID. The data gathered from labels is then Data is put away inside the RFID label's microchip that is associated with a reception apparatus

- The label chip contains a memory which stores the item's electronic item code and other variable data

- $\quad$ The RFID peruser is a system associated gadget with a reception apparatus that peruses and tracks the data from RFID labels [6].

- Information gathered from the labels is then moved through a PC framework, where the information can be put away in a database and dissected later.

- $\quad$ RFID is utilized in many enterprises however it is the core of the production network the executive's procedure.

- It is moved through an arrangement of the PC where information can undoubtedly be spared in a database and deciphered. RFID is used in ventures yet it is the core of the SCM procedure [5].

There are some important considerations for executing an RFID, this information might be capable to read through anyone that is well-matched reader and outcome in less privacy and security. It is difficult to attain commitment from a professional and partners of the supply chain due to without them a project is sure for being failed [11]. The pricing for implementing RFID in a SCM is high and it may result in roadblock for purpose of undertaking of technology. The new technology may not be present to a supplier. The RFID system includes three main components [4]:

- The coil or antenna

- The transceiver with having a decoder [17]

- The RF tag element transponder is programmed in an electronic way with having a particular information

The radio signs are additionally transmitted by reception apparatus enacts a tag and guys to compose and understand information. The reader sends the rushes of radio dependent on a force result to a removed spot from an inch to a hundred feeds. The RFID tag at the hour of entering an electromagnetic zone, it looks at the initiation sign of a readers [7]. The data is encoded in an integrated tags circuit that is decoded through sent and reader to a host computer for the purpose of processing. The transmitted data also present information about a price, location, colour of product and date of purchase etc. The RFID tag has a microchip that is connected to the radio receiving wire that can peruse two kilobytes of information. The peruser 
explicitly has at least one radio wire that supports recovering information that is put away in the tag [5].

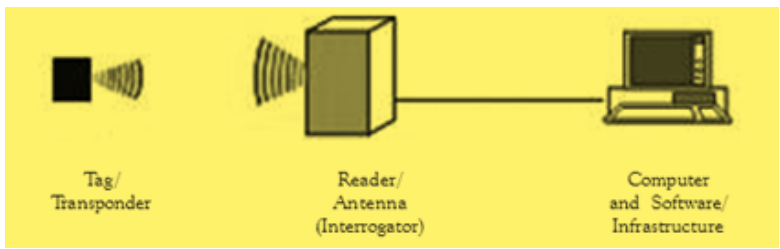

Fig. 2. RFID Tag Transponder Functionality

The RFID has an effective contribution to the execution of the inventory network. It deals with a procedure of production network adequately and bolsters the organization to develop. The procedure of the store network might be alluded to as a chain comprising of the provider, producer, transporters, merchants, retailers and retail clients [13].

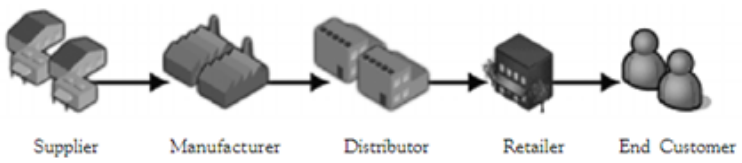

Fig. 3. Procedure of Store Network

The inventory network the board might be alluded to as overseeing exercises that can be completed for changing an assistance or item from a degree of the production network to another. The suitable coordination and arranging are expected to arrive at clients and fulfill them. The significant issue is a degree of stock is for keeping up at a degree of the production network [16] [20]. The issues that are identified with stock, for example, stock-outs, abundance stock, wastage of materials., wellbeing, loss of offers and burglary and so forth may affect the adequacy of the store network strategy. The procedure of the inventory network can have various providers, stockrooms, retailers, transporters and merchants [16]. It introduces an entangled procedure of store network and level of trouble for being overseen. The administrations and items from the maker to end-clients it's expense and qualities at included a degree of inventory network process. The proficient and viable store network has a plausibility if there is a sufficient progression of data at the degree of the production network technique and satisfactory stock being regulated. Every level has a track of expected and actual sales and stock [12]. The customers have become trendy and demanding. They desire the service and products that they use to purchase. So, they have a maximized efficiency to meet the customer demand over time. The RFID is basically a technology that permits for solving some problems to meet the customer's demand in an efficient way [14] [20].

RFID technologies and applications are evolving and diverse in a rapid way. RFID technologies vary in the context of abilities for instance, memory capacity, size and range of capacity. The individual RFID application involves a range of various operations and sectors of industry [14]. The attempts to concentrate and support effort over specific technologies or applications it may diminish the resource for revenues and distort the market for equipment and elements. The government policies help in expanding and using the benefits of RFID and it must not favour technology or the application over another [2] [12].

RFID can result in autonomous warehouses and centers of distribution. This is observed in warehouses with an increased automation level, in which picking machines transport the bind of products to a central area of sorting prior to returning to its location [9]. A frequency that is used for the application of RFID is a significant characteristic of RFID Systems. The diversity by regulation through the country for purpose of RFID allocation while it is being placed. The major problem in an RFID system is the presence of various standards., The national allocation for the RFID is a main issue to an application of system of RFID in the world and it is a major problem to technologies in the context of standardization. The high frequency presents reading distances and fasters the communication. The lower-recurrence inactive labels have a viable kind range that is around $30 \mathrm{~cm}$, the high-recurrence latent labels are essential in range for $1 \mathrm{~m}$ [4]. The UHF is known as ultra-high frequency passive tags that have the appropriate range of $8 \mathrm{~m}$. The dynamic labels are self-controlled and costly than uninvolved labels however it can achieve a scope of $100 \mathrm{~m}$ [5] [21].

RFID innovation is conceivable and present in the territory of human action. The assortment of undertakings is using RFID for improving the productivity of tasks and accomplishing an upper hand. The advancement inside RFID is absent in innovation however its utilization within the process is a real business [7] [25]. The quick development and growth of advancement and development of Information innovation and diminishing costing of RFID framework segments has introduced a steady extension of use areas. The utilization of RFID innovation in inventory network the board have accomplished explicit consideration in years. The common RFID applications are real-time warehouse operation planning process, product development, solving the materials of production and demand for the issues within a manufacturing environment [9]. However, it can be said that emerging IT and implementation of RFID within an organisation either within different sectors have a positive impact on the internal supply chain management. However, categories of the tags are available while it also has various benefits and challenges that are most commonly faced by the industries by adopting RFID technologies and implementing them in their supply chain sector [4].

\section{Methodology}

This chapter presents the understanding of the method that is adopted by the organisation and IT sector to affect the internal SCM through implementing RFID. This also presents the research design, quantitative approach, validity, reliability, sampling size, the method used, and ethical considerations that are undertaken for promoting the authenticity of the research.

It is an action plan that helps in providing the adequate efforts and understanding, enabling to carry out the research in a systematic way and on schedule to provide the quality result and detailed reporting for showing the research [3].

The quantitative survey is referred to as a method in the research of a business, or research related to an organisation 
that supports and permits access to a high number of participants. The quantitative method is an appropriate method of research that provides a response through a wide or small range of participants [17]. The development of the question also seems to be simple, and develops the meaningful questionnaire that supports for answering the research question is tough. The questionnaire requires appealing to respondents that may not belong and intrusive but tough to understand [6]. They also require to measure an accurate way, the issue in an investigation. It is also advised while possible for using a questionnaire that is present on the market and has already been validated. Using the decisions of the questionnaire, it is important to take the sample size under consideration and representative as the population studied. The surveys may be administered to a whole population for employees of a specific organisation [19].

The total number of participants selected for the study is 50 in number. The simple random sampling method is used for the research study. It is a subset of a statistical population in which every member of the subset has the same probability of being elected [7]. It is meant to be an unbiased representation of the team or group. This method is used for smaller sample sizes from the larger population and uses it to research and making the generalization about a larger group. The privilege of this sampling strategy involves its ease of use, accurate representation of a large population.

The content chosen for the study is a literature review and quantitative research that is an objective study carried out through survey responses. The content for literature is chosen from an accessible site, these included books, journals, articles and published materials within libraries. The data is reliable and valid because all data gathered is from the previous seven years of published materials.

The data was gathered from participants by distributing the survey questionnaires among 50 participants. There was a total of 52 participants, among which two of them have declined to participate within a research while, the data for questioner or survey was selected from SPSS and presented in geographical and chart formats.

Ethics is an important part of the research study. The ethical consideration includes five different elements [5]. The confidentiality of the participant was maintained during the survey, the participants were given autonomy to decline to be a part of research if they face any harm or issue, the principle of non-maleficence and beneficence were maintained, this presents that no participants were harmed either physically or psychologically. The research was carried out for the benefits of organisations instead of benefiting researchers [7]. While the fidelity principle was also maintained. However, all participants had voluntary participation, no participant was forced to be a part of research every individual by its own willed to be a part of a research study. However, to ensure this, informed consent was distributed and signed which is a permission letter and assured of the safety of personal information.

\section{A. Research Hypothesis}

- H1: Internal SCM of an organization has been enhanced by RFID due to its Automatic Identification

- H2: Internal SCM of an organization has been enhanced by RFID due to its Mass Scanning System

- H3: Internal SCM of an organization has been enhanced by RFID due to its Efficient Integrated System

\section{ANALYSIS}

This section presents the interpretation through SPSS this reveals the statements and analysis on basis of Likert's Chart.

\section{A. Findings of Survey}

The histogram below presents that RFID technology supports reducing the overproduction by mean of being aware of goods and materials present within the stock. It is true as evaluated from literature, 17 participants strongly agreed with this statement. Because it can help to reduce down the overproduction and save from wastage.

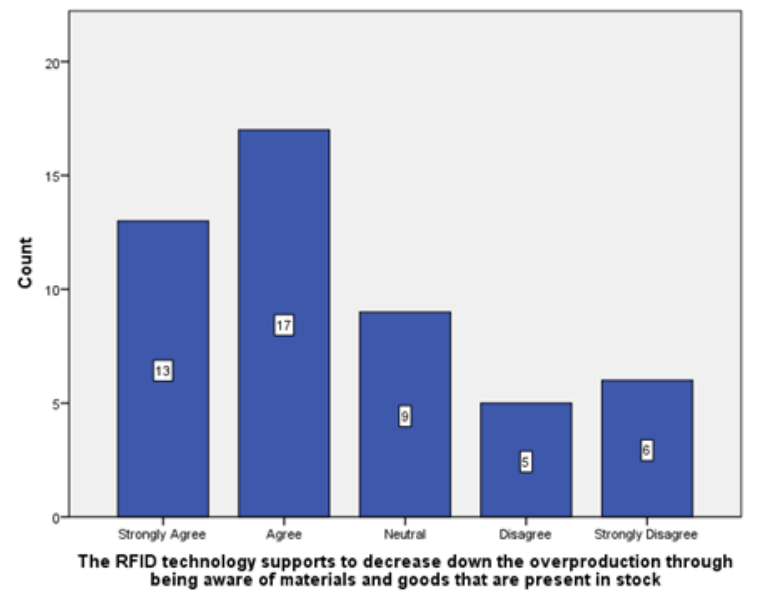

The second histogram presented below shows a high score of strongly disagreeing for which 15 participants said that supply chain supports in determining the category of product that is needed as a product or service that customers use to predict the amount and timing demand of the customer. Only 13 participants disagreed and only 6 of them agreed with the statement.

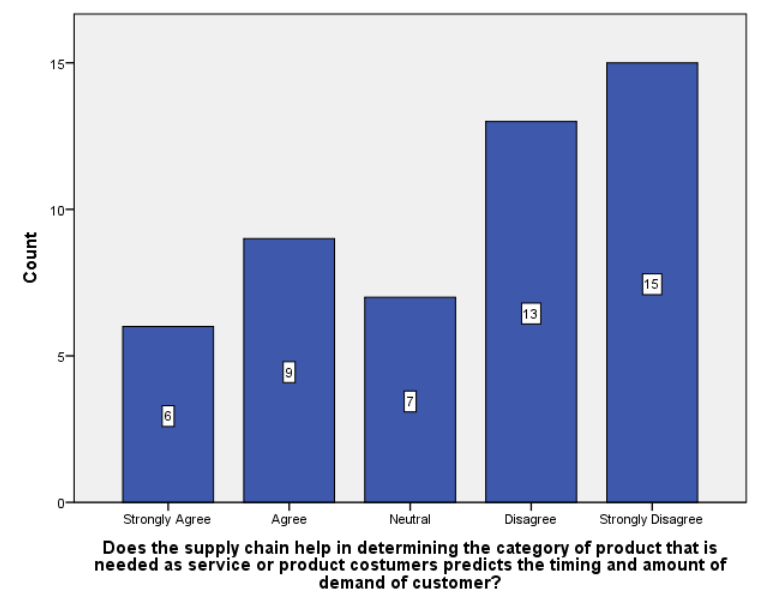


The 17 participants agreed with the statement that supply chain uses to meet the demanding needs while, managing a cost of inventory in an effective way, 14 participants sat neutral, 8 disagreed, 7 strongly disagreed and 4 strongly agreed with the statement.

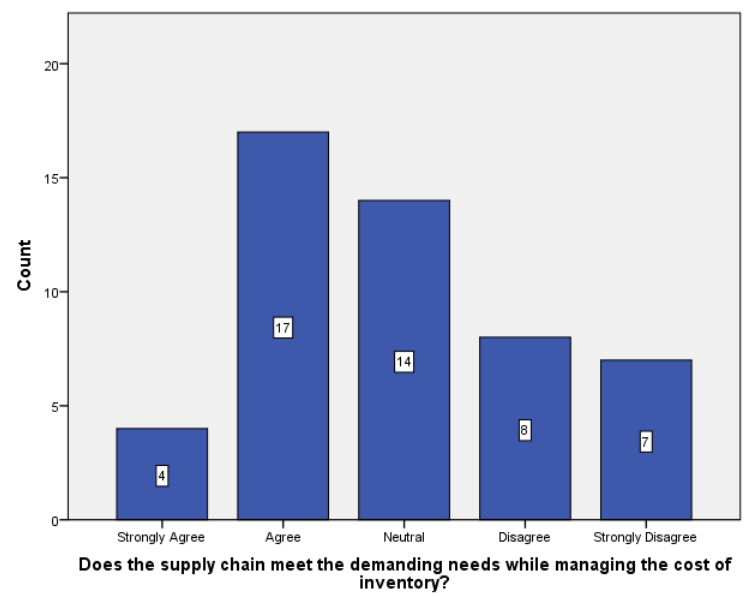

The total 12 participants disagreed with the statement, that RFID does not possess' advantages for example, the increased capability for storage, repeated writing, remote reading, and improved data security. The 10 strongly disagreed, 11 agreed and 9 set neutral while, 8 strongly agreed with the statement.

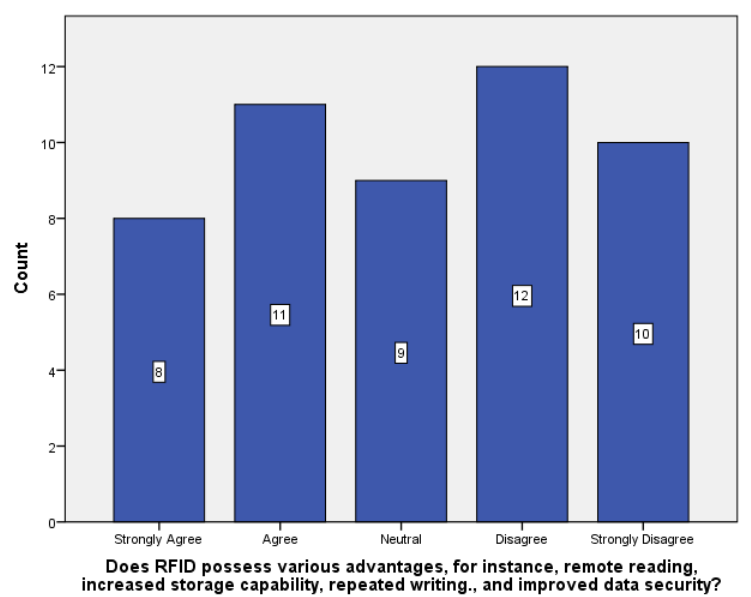

The 17 participants in total presented that It adds value to services and products is a common advantage for adopting RFID. The 15 presented that it improves customer service and decreased time, 9 said that it helps in cost distribution material handling and poor quality while rest 9 also presented that it helps to change a business.

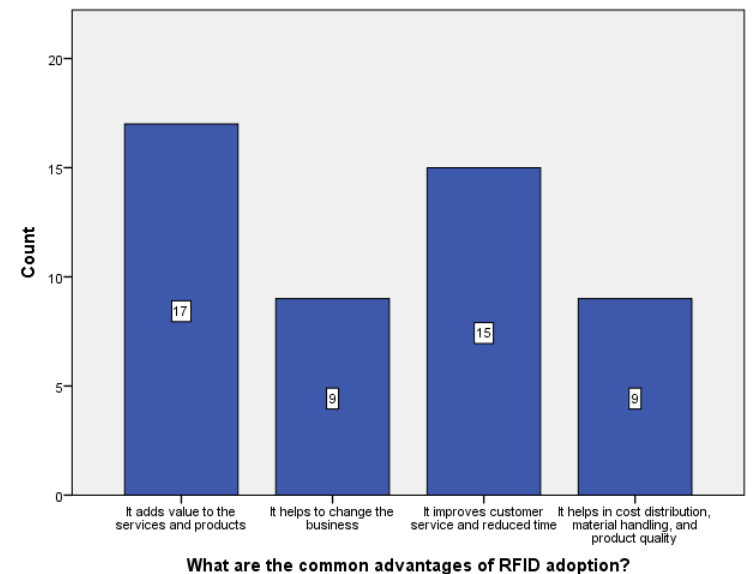

The 19 participants revealed that IT RFID improvements help to improve the inbound services for managing a supply chain, 19 participants agreed that it needs to make improvement by integration and adoption of easy services, while, 12 participants agreed that improvement can be bought in ISCM by processing a need for improvement.

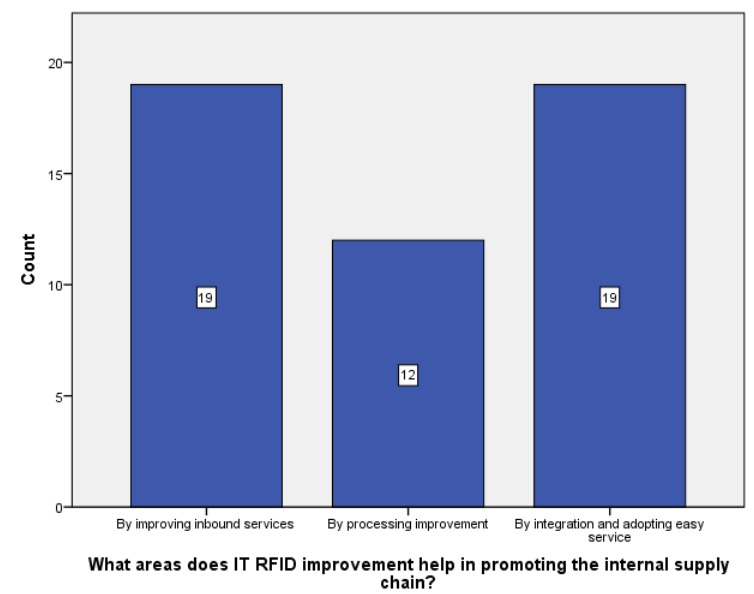

The below graph shows, the majority of 13 participants sat Neutral that the use of RFID technology support reduces down the unnecessary inventory through improving the visibility.

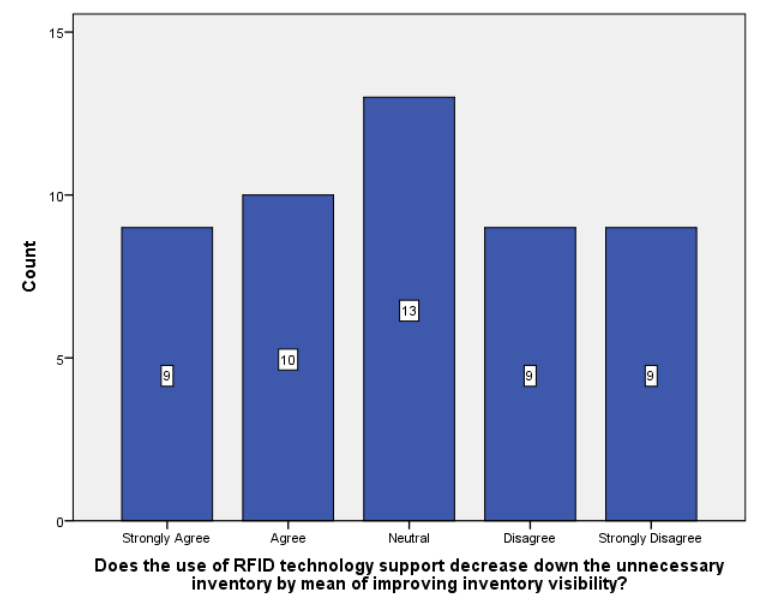

The below graph shows 18 participants said that supplier relationship management is a category, 18 presented CRM, and 14 revealed internal supply chain management. 


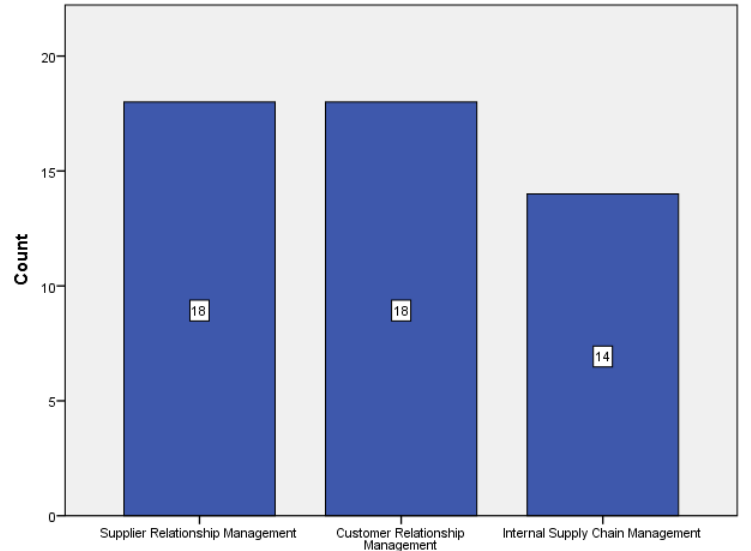

Do supply chain activities are divided into three main types?

The below graph shows 16 participants strongly disagreed with the statement that SCM of the organisation has improved by RFID due to the purpose of Automatic Identification. While the scores for other participants were minimum that responded to the question.

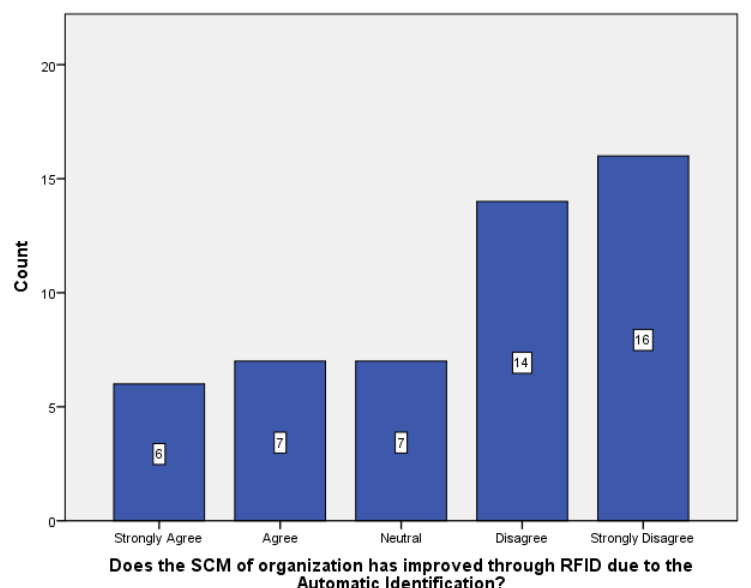

The 17 participants in total agreed that SCM of an organisation has been promoted through adopting RFID due to a MASS SCANNING SYSTEM, they revealed it as an effective method, while 14 also strongly agreed with the statement.

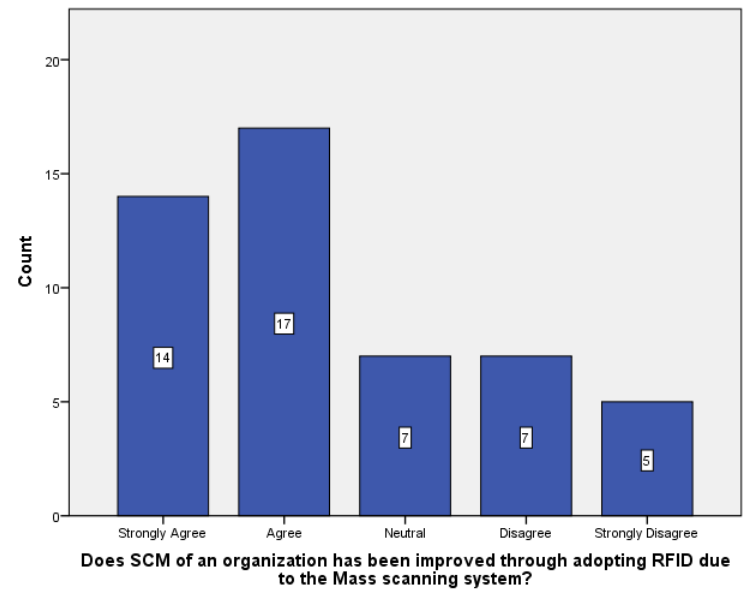

The 16 participants in total agreed with the statement, that SCM of organisation support for enhancing RFID by an efficient integrated system. While, 10 strongly agreed, and 9 set neutral, 7 strongly disagreed and 8 only disagreed with the statement.

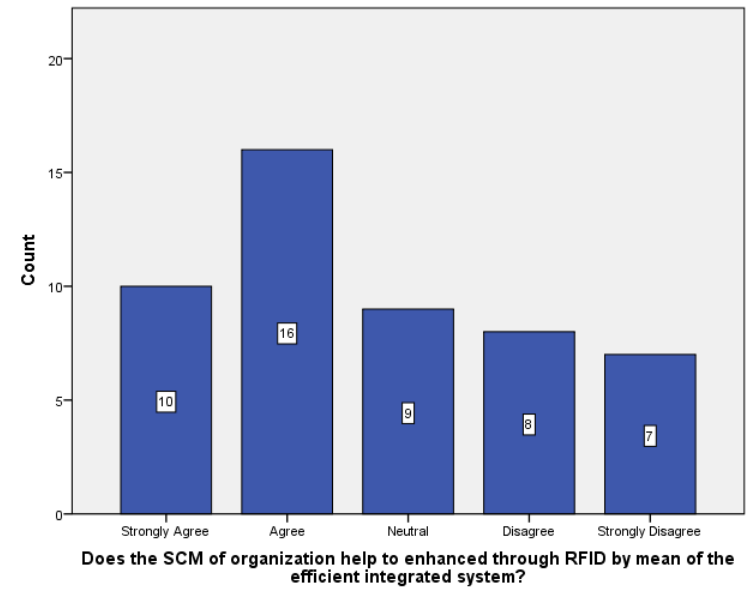

The most preferred element within SCM for carrying out and implementing RFID is data transfer that is respondent by 35 participants., and 15 revealed scanning devices.

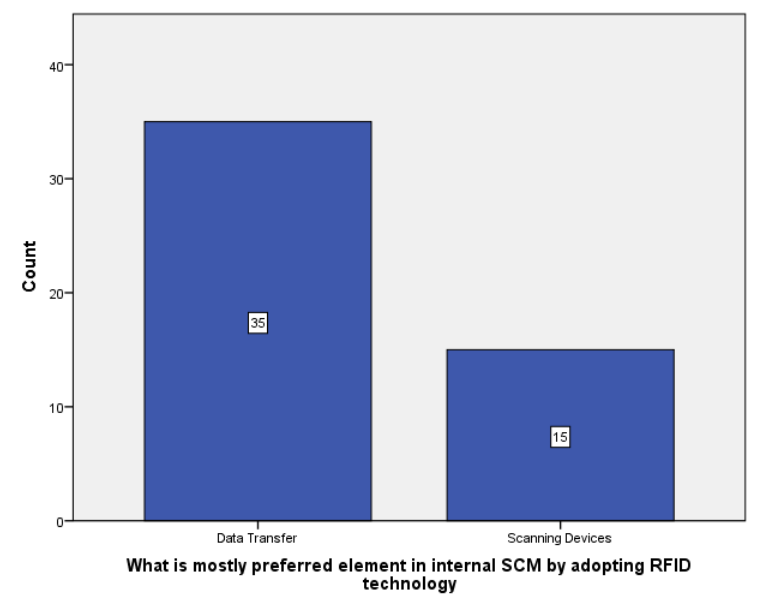

The graph below shows the 19 number of participants strongly disagreed that they do not believe in a Mass scanning system to be adequate for tags detectability.

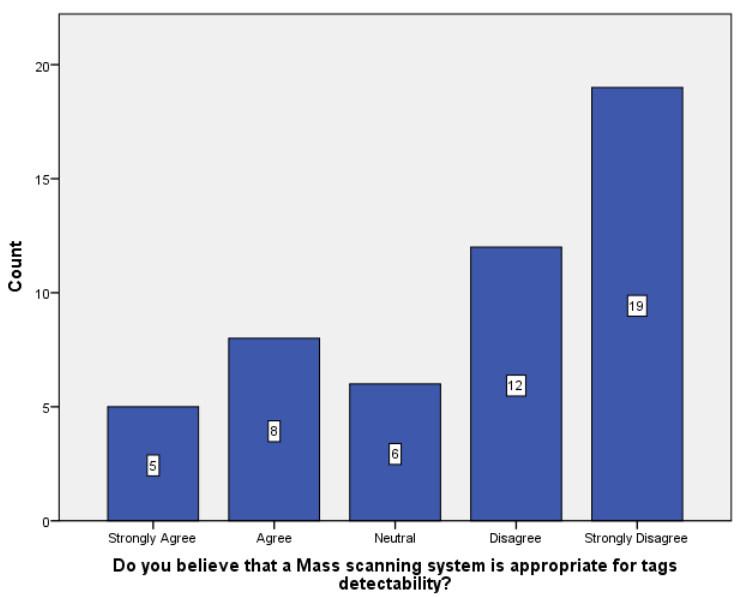

The graph below shows the total 24 participants strongly Disagreed with the statement that automatic identification helps in the time efficiency and constraints. While 14 agreed with the statement. 


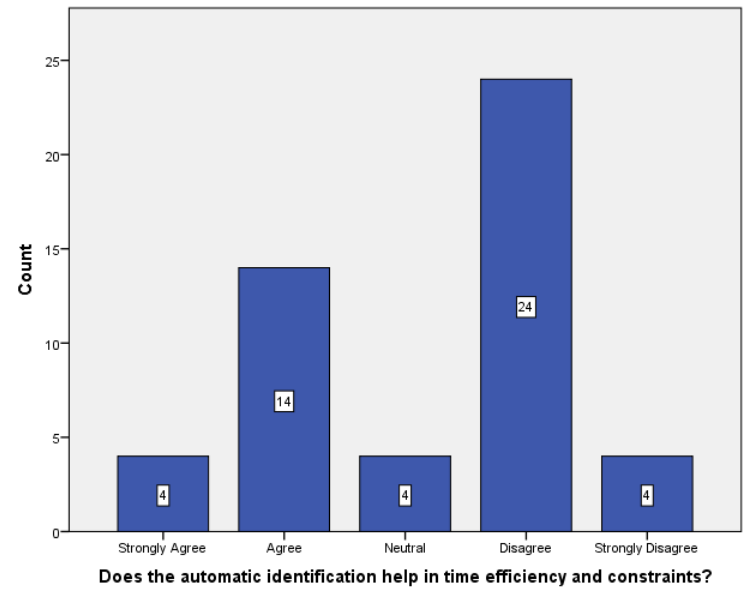

The graph below shows the total 16 participants Disagreed with the statement that an integrated system helps in better communication and accessibility of data, while, 11 agreed and rest had a minimum score.

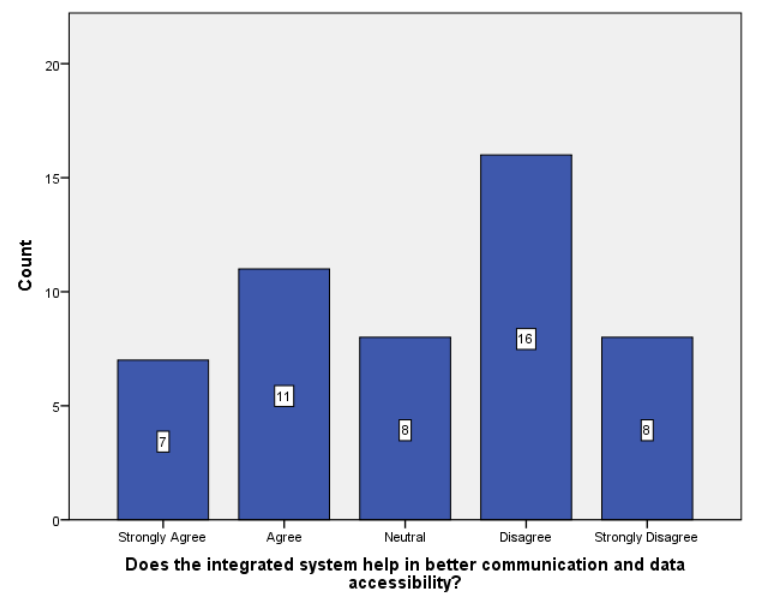

\section{DISCUSSION}

The data from analysis revealed RFID tags implementation having various benefits within a supply chain of an organisation. However, the IT sector creates a positive impact of SCM but only data confidentiality, transfer and privacy are the major threats that are measured [14]. There are certain benefits for the organisation that executes an RFID technology within a process of business. It helps to promote supply chain performance specifically due to providing managers with real-time data that improves the process of decision making [24]. It enables sufficient and efficient materials, management and controls by decreasing down the flow of materials, which ultimately ensures a product that is positioned in right place at the proper time and helps to decrease down the level of inventory and minimize the overstocking warehouses and centers of distribution. It helps in facilitating proactive practices and planning, while, permits the forecasting demand for goods accurately and estimates are grounded on real-time data [19]. It helps to promote and strengthens the relationship with customer-supplier through fostering communication and sharing information among suppliers, business firms and the customers.

The inventory management is promoted as readers and tags that may be programmed in a way that an automatic signal is sent while replacements order is required [18]. The communication through a two-way mean can make possible for shipment orders, as a priority for the customers. It helps to mitigate the cost through decreasing labour and time needed for manual input of data. These systems help to promote the accuracy of data, that benefits operations and sales planning and practical way to support firms afloat the economic climate. The cost saving is another element the estimated saving of $30 \%$ of 2 to $4 \%$ in operation expense that is typically spent over costs of distribution and warehouse.

\section{CONCLUSION}

The paper addresses the effect of IT on ISCM of an organisation and its functioning, the implementation of RFID tags has various benefits within supply chain management, it promotes, cost efficiencies, effectiveness and various other elements. According to the research studies, RFID is a way to future, while the future belongs to a solution that is innovative, flexible and affordable and offers enhanced customer service. RFID is perfect and matches the futuristic solution. It is a most promising, anticipated and evolving solution that is executed within the recent duration while, demand and the rise in the technological advancement has supported the E-commerce and concept of M-commerce needs management, inventory and RFID is one that has a core potential for increasing the return on investment to serve the customer in a faster way, it increases accuracy and reliability, at the similar time, it improves an SCM process. The survey interpreted that the major benefit of RFID tags implementation is data transfer can easily be done, However, there are three main activities of supply chain management as interpreted from the survey.

There are various areas in which the research can be carried out. These include a bar code system, RFID system and implementation process, improvements that could be made in chip and other areas. However, the research can also be carried out in the healthcare sector, aviation sector, wholesalers and various other industries of food chain restaurants and suppliers. The future implications have various benefits to be evaluated. Implementing RFID systems and RFID tags are effective for promoting the worth and value within the interior supply chain sector.

\section{REFERENCES}

[1] Barata, J., Rupino Da Cunha, P. and Stal, J., "Mobile supply chain management in the industry 4.0 era: an annotated bibliography and guide for future research" Journal of Enterprise Information Management, 31(1), pp.173-192, year 2018.

[2] Cole, R., Stevenson, M. and Aitken, J., "Blockchain technology: implications for operations and supply chain management" Supply Chain Management: An International Journal, 24(4), pp.469-483, year 2019

[3] Costa, F., do Sameiro Carvalho, M., Fernandes, J.M., Alves, A.C. and Silva, P., "Improving visibility using RFID-the case of a company in the automotive sector" Procedia Manufacturing, 13, pp.1261-1268, year 2017.

[4] Fahmy, A., Altaf, H., Al Nabulsi, A., Al-Ali, A. and Aburukba, R., "March. Role of RFID Technology in Smart City Applications" In 2019 International Conference on Communications, Signal Processing, and their Applications (ICCSPA) (pp. 1-6). IEEE, year 2019.

[5] Figorilli, S., Antonucci, F., Costa, C., Pallottino, F., Raso, L., Castiglione, M., Pinci, E., Del Vecchio, D., Colle, G., Proto, A. and Sperandio, G., "A blockchain implementation prototype for the 
electronic open-source traceability of wood along the whole supply chain" Sensors, 18(9), p.3133, year 2018.

[6] Freitas, A.C., Maio, A.F., Maia, P., Gomes, N., Nogueira, A. Fernandes, J.M. and Machado, S., "Savings in internal logistics using a RFID-based software system in a lean context" In Proceedings of International Conference on Computers and Industrial Engineering, CIE, year 2017.

[7] Green Jr, K.W., Zelbst, P.J., Sower, V.E. and Bellah, J.C., "Impact of radio frequency identification technology on environmental sustainability" Journal of Computer Information Systems, 57(3), pp.269-277, year 2017.

[8] Gunasekaran, A., Subramanian, N., Tiwari, M.K., Yan, B., Yan, C., Ke, C. and Tan, X., "Information sharing in supply chain of agricultural products based on the Internet of Things" Industrial Management \& Data Systems, year 2016.

[9] Hofmann, E. and Bosshard, J., "Supply chain management and activity-based costing: Current status and directions for the future" International Journal of Physical Distribution \& Logistics Management, 47(8), pp.712-735, year 2017.

[10] Khan, D. and Milan, M., "Supply Chain Management (SCM) Revealing Quality Services in University Libraries: Experience and Realization", year 2016.

[11] Khan, S.A.R., Golpîra, H. and Zhang, Y.U., "The importance of advanced information technology and green vehicles in supply chain management" DEStech Transactions on Computer Science and Engineering, (ccme), year 2018.

[12] Lee, I., "A conceptual framework of the Internet of Things (IoT) for smart supply chain management" In Encyclopedia of e-commerce development, implementation, and management (pp. 1177-1189). IGI Global, year 2016

[13] Li, Z., Liu, G., Liu, L., Lai, X. and Xu, G., "IoT-based tracking and tracing platform for prepackaged food supply chain" Industrial Management \& Data Systems, 117(9), pp.1906-1916, year 2017.

[14] Marinagi, C., Skourlas, C. and Galiotou, E., "November. Advanced information technology solutions for implementing information sharing across supply chains" In Proceedings of the 22nd PanHellenic Conference on Informatics (pp. 99-102). ACM, year 2018.

[15] Monteleone, S., Sampaio, M. and Maia, R.F., "A novel deployment of smart Cold Chain system using 2G-RFID-Sys temperature monitoring in medicine Cold Chain based on Internet of Things" In 2017 IEEE International Conference on Service Operations and Logistics, and Informatics (SOLI) (pp. 205-210). IEEE, year 2017.

[16] Moons, K., Waeyenbergh, G. and Pintelon, L., "Measuring the logistics performance of internal hospital supply chains-A literature study" Omega, 82, pp.205-217, year 2019.

[17] Nabelsi, V. and Gagnon, S., "Information technology strategy for a patient-oriented, lean, and agile integration of hospital pharmacy and medical equipment supply chains" International Journal of Production Research, 55(14), pp.3929-3945, year 2017.

[18] Oghazi, P., Fakhrai Rad, F., Karlsson, S. and Haftor, D., "RFID and ERP systems in supply chain management" European Journal of Management and Business Economics, 27(2), pp.171-182, year 2018.

[19] Reyes, P.M., Li, S. and Visich, J.K., "Determinants of RFID adoption stage and perceived benefits" European Journal of Operational Research, 254(3), pp.801-812, year 2016

[20] SANTONINO III, M.D., Koursaris, C.M. and Williams, M.J., "Modernizing the Supply Chain of Airbus by Integrating RFID and Blockchain Processes" International Journal of Aviation, Aeronautics, and Aerospace, 5(4), p.4, year 2018.

[21] Smith, A.D., Rupp, W.R. and Manna, D.R., "Case Studies of Green Supply Chains and Enabling RFID Technology" year 2019.

[22] Suguna, S.K. and Kumar, S.N., "Application of Cloud Computing and Internet of Things to Improve Supply Chain Processes" In Edge Computing (pp. 145-170). Springer, Cham, year 2019.

[23] ten Hompel, M., Masoudinejad, M., Bousbiba, O. and Roidl, M., "Automatic Identification Technology". In Operations, Logistics and Supply Chain Management (pp. 687-718). Springer, Cham, year 2019.

[24] Valverde, R. and Talla, M., "RFID Implementation of Supply Chain: Comparison of Three Case Studies" Available at SSRN 2822142, year 2016.

[25] Wu, L., Yue, X., Jin, A. and Yen, D.C., "Smart supply chain management: a review and implications for future research" The International Journal of Logistics Management, 27(2), pp.395-417, year 2016.

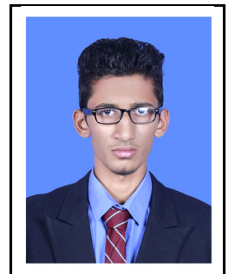

Mr. Shaharyar Khan was born in July, 1995 in the city of Karachi, Pakistan. A technology lover working on different ideas of implementing IT in Supply Chain Management.

He has done MBA in Supply chain management from Karachi University Business School, 2020. Previously he has done BS in Computer Science from Sindh Madressatul Islam University, 2017.

He is serving as a Project Manager at Hashone Creatives in Karachi. Previously was working as a Business Development Executive at Hashone Creatives. 